\title{
Steroidogenic factor 1-DNA binding: a kinetic analysis using surface plasmon resonance
}

\section{Bryan, S J B Aylwin, D J Newman and J M Burrin}

\author{
Department of Clinical Biochemistry, St Bartholomew's and the Royal London School of Medicine and \\ Dentistry, Turner Street, London E1 2AD, UK
}

(Requests for offprints should be addressed to J M Burrin)

\begin{abstract}
Basal expression of the glycoprotein hormone $\alpha$-subunit gene in pituitary gonadotrophs is partially dependent on a gonadotroph specific element (GSE) which binds the nuclear receptor, steroidogenic factor-1 (SF-1). We have used surface plasmon resonance $(\mathrm{SPR})$ to determine the association $\left(k_{\mathrm{ass}}\right)$, dissociation $\left(k_{\text {diss }}\right)$ and affinity $\left(K_{\mathrm{A}}\right)$ constants of SF-1 binding to immobilized oligonucleotides containing either the GSE consensus motif or a GSE mutant with a 2 bp substitution in the GSE site $\left(\mathrm{GSE}_{\mathrm{MUT}}\right)$.

In vitro translated $\mathrm{SF}-1$ protein bound the consensus GSE with a threefold increase in affinity constant $(P<0 \cdot 01)$ compared with the $\mathrm{GSE}_{\mathrm{MUT}}$. This was due primarily to a significant increase $(P<0 \cdot 05)$ in the $k_{\text {ass }}$ for SF-1 to the GSE and a slower $k_{\text {diss }}$ $(P<0 \cdot 05)$. The binding interaction was specific and could be significantly inhibited $(P<0 \cdot 001)$ by either
\end{abstract}

anti-SF-1 antibody or excess non-biotinylated GSE. The addition of $14 \mathrm{bp}$ wild-type flanking sequences significantly reduced the affinity of SF-1 to both the GSE $(P<0 \cdot 05)$ and the $\mathrm{GSE}_{\mathrm{Mut}}$ $(P<0 \cdot 01)$. This was due to a significant $(P<0 \cdot 01)$ decrease in $k_{\text {ass }}$ for the wild-type and mutant long oligonucleotides compared with the short GSE. Nuclear extracts from $\alpha \mathrm{T} 3-1$ gonadotroph cells also bound the GSE and $\mathrm{GSE}_{\mathrm{MUT}}$, giving $k_{\text {diss }}$ values which were two- to threefold slower than those obtained with in vitro translated SF-1.

Thus, SPR is a powerful technique for examining kinetic interaction between SF-1 and its binding site, and is able to demonstrate the effects of mutations and flanking sequences on that interaction.

Fournal of Molecular Endocrinology (1999) 22, 241-249

\section{INTRODUCTION}

Steroidogenic factor (SF-1) is one of two proteins expressed from the mouse homologue of the Drosophila fushi tarazu-factor 1 (Ftz-F1) gene (Lala et al. 1992). SF-1 is also known as adrenal-4binding protein $(\mathrm{Ad} 4 \mathrm{bP})$ and gonadotroph-specific element binding protein 1 (GSE-B1) (Morohashi et al. 1992, Horn et al. 1992). It was revealed by cloning to be highly homologous to members of the nuclear receptor family, especially in the zinc-finger DNA-binding domain (Laudet et al. 1992, Wong et al. 1996). Expression of SF-1 occurs in a cell-selective manner, and has been shown to be necessary for the expression of steroid enzymes in the adrenal cortex and gonad (Parker \& Schimmer 1996). Until recently, putative ligands for SF-1 had not been identified but selective endogenous oxysterols have now been shown to be transcriptional activators of SF-1 activity in vitro and this data suggest that SF-1 may be a ligand-activated receptor (Lala et al. 1997). Whether oxysterols bind SF-1 directly or indirectly remains unknown, as do the mechanisms involved and the biological significance of the interaction.

Although little is known about the molecular mechanisms involved in the control of SF-1 cell-specific expression, various studies have shown that SF-1 is an essential determinant of adrenal and gonadal development, male sexual differentiation and formation of the ventromedial hypothalamic nucleus (Parker \& Schimmer 1996). In the adult mouse, SF-1 is constitutively expressed in the hypothalamus, adrenal cortex, pituitary gonadotroph, testis and the thecal and granulosa cells of the ovary (Barnhart \& Mellon 1994). In addition to these observations, SF-1 has been shown to regulate a number of genes including the luteinizing hormone $\beta$-subunit gene and the glycoprotein hormone $\alpha$-subunit $(\alpha$-SU) gene in pituitary 
TABLE 1. Oligonucleotide sequences used in SPR studies

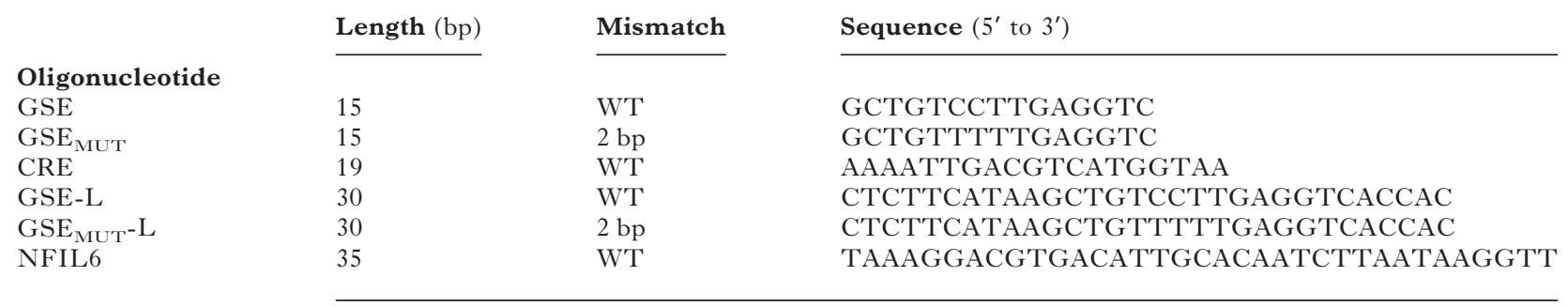

WT, wild-type.

gonadotrophs (Barnhart \& Mellon 1994, Halvorson et al. 1996).

During the development of the anterior pituitary, five endocrine cell types are produced: gonadotrophs, thyrotrophs, corticotrophs, somatotrophs and lactotrophs, each producing specific hormones. Gonadotrophs produce luteinizing hormone (LH) and follicle-stimulating hormone (FSH), whilst thyrotrophs produce thyroid-stimulating hormone (TSH). These three hormones are heterodimers made up of the glycoprotein (gp) hormone $\alpha$-subunit non-covalently associated with the distinct $\beta$-subunits. The gp $\alpha$-SU gene is the common element in this family of glycoprotein hormones and is the earliest of the hormone genes to be expressed in the developing mouse pituitary (Simmons et al. 1990, Japon et al. 1994). Expression of the $\alpha$-subunit gene in pituitary gonadotrophs involves a gonadotroph specific element (GSE), conserved in all mammalian $\alpha$-subunit genes, which has been shown to bind to SF-1 in $\alpha \mathrm{T} 3-1$ cells (a mouse clonal gonadotroph cell line) (Horn et al. 1992, Barnhart \& Mellon 1994). However relatively little is known about the molecular mechanisms involved in the control and expression of the SF-1 gene in the gonadotroph or of the regulation by SF-1 of gonadotroph-specific genes.

In order to understand the role of SF-1 in the regulation of endocrine differentiation and function, several areas need to be addressed, including the interaction of SF-1 with other transcription factors and various binding motifs. In this investigation, the interaction between SF-1, the mouse GSE consensus motif TGTCCTTG and a GSE mutant $\left(\mathrm{GSE}_{\mathrm{MUT}}\right)$ have been studied using surface plasmon resonance or biosensor technology. Biosensor technology exemplified by the BIAcore allows analysis in 'real time' of molecular interaction, for example protein-protein or DNA-protein interactions (Bondeson et al. 1993, Johne et al. 1993, Malmborg et al. 1995). Studies of protein-DNA interactions have shown that this technique permits reproducible measurements of binding kinetics which are not feasible using other methods (Bondeson et al. 1993, Malmborg et al. 1995). The interactions between two macromolecules, one immobilized, is analyzed and quantitated in terms of their association and dissociation rates and hence affinity for each other. The results presented here demonstrate differences between the interaction of SF-1 with its putative binding site, the GSE and a $\mathrm{GSE}_{\mathrm{MUT}}$.

\section{MATERIALS AND METHODS}

\section{Instrumentation and reagents}

The BIAcore sensorchip CM5, Tween-20 surfactant (P20) and amine coupling kit containing N-hydroxysuccinimide (NHS), N-ethyl-N'(3-diethylaminopropyl) carbodiimide (EDC) and ethanolamine hydrochloride were obtained from BIAcore (Uppsala, Sweden). Immunopure neutrAvidin was obtained from Pierce and Warriner (Rockford, Illinois, USA). Rabbit polyclonal antibody to SF-1 was obtained from Upstate Biotechnology (Lake Placid, New York, USA).

\section{Oligonucleotides}

Oligonucleotides (Table 1) representing the mouse alpha subunit ( $\alpha-\mathrm{SU})$ gene gonadotroph specific element (GSE) - the wild type SF-1 binding site, a mutant with a 2 bp substitution in the GSE site $\left(\mathrm{GSE}_{\mathrm{MUT}}\right)$, and a negative control oligonucleotide, the human $\alpha$-SU cyclic AMP response element (CRE) (Deutsch et al. 1987) were synthesized and purified by HPLC ( $\mathrm{R}$ and $\mathrm{D}$ Systems Ltd, Abingdon, Oxon, UK). Oligonucleotides were synthesized with and without a $5^{\prime}$ biotin group for the wild-type SF-1 binding site (GSE), and the 15 bp mutant described $\left(\mathrm{GSE}_{\mathrm{MUT}}\right)$. In addition, two longer oligonucleotides $(30 \mathrm{bp})$ containing flanking sequences, GSE-L and $\mathrm{GSE}_{\mathrm{MUT}}-\mathrm{L}$ were synthesized. As a control for non-specific binding, a 35-base pair oligonucleotide (NFIL6) was synthesized (Table 1). This sequence represents the binding site for the unrelated transcription factor 
NFIL6, a member of the CCAAT/enhancerbinding protein family (Akira et al. 1990). Each biotinylated oligonucleotide and its nonbiotinylated complementary sequence were diluted to $70 \mathrm{pM}$ (1:1 ratio) in $10 \mathrm{mM}$ Hepes, $150 \mathrm{mM}$ $\mathrm{NaCl}, 3.4 \mathrm{mM}$ EDTA and $0.5 \mathrm{~g} / 1$ surfactant P20 (Hepes buffered saline (HBS)) $\mathrm{pH} 7 \cdot 4$ (all supplied by Aldrich, Poole, Dorset, UK). Oligonucleotides were heated to $70{ }^{\circ} \mathrm{C}$ and allowed to anneal by cooling slowly to room temperature.

\section{Protein expression}

The expression vector pGex-1 lambda $T$ was obtained from Pharmacia Biotech (Uppsala, Sweden). The procedure used to obtain the glutathione $\mathrm{S}$ transferase (GST)-SF-1 fusion protein was as previously described (Malim \& Cullen 1991). Briefly, SF-1 full length cDNA (kindly donated by K Parker, Duke University, North Carolina, USA), was excised from blue script $(\mathrm{pBS}+)$ using EcoRI and sub-cloned into the expression vector pGex-1 lambda $T$. The recombination-deficient $E$. coli strain DH5 $\alpha$ obtained from ClonTech (Palo Alto, CA, USA) was used for all subsequent transformations. A single colony shown by restriction endonuclease digestion to contain SF-1 DNA, was used to inoculate $10 \mathrm{ml}$ Luria-Bertani (LB) medium (Life Technologies, Paisley, Strathclyde, UK) and the culture was grown for $12-18 \mathrm{~h}$ at $37^{\circ} \mathrm{C}$ with shaking. A $1: 10$ dilution of the overnight culture was then used to inoculate fresh prewarmed medium and the culture grown until the optical density at $600 \mathrm{~nm}\left(\mathrm{O} . \mathrm{D}_{600}\right)$ was between 0.6 and $1 \cdot 0$. Isopropylthiogalactopyranoside $(100 \mathrm{mM})$ (Life Technologies) was added to a final concentration of $0.1 \mathrm{mM}$ and the incubation continued for a further $2 \mathrm{~h}$, after which time the culture was pelleted by centrifugation at $250 \boldsymbol{g}$ at $4{ }^{\circ} \mathrm{C}$ for $30 \mathrm{~min}$. The cell pellet was then resuspended in $50 \mathrm{mM}$ Tris- $\mathrm{HCl}$ to which $100 \mathrm{mg} / \mathrm{l}$ lysozyme (Aldrich), Triton X-100 and Tween-20 (Aldrich) (both at a final concentration of $10 \mathrm{~g} / \mathrm{l}$ ) were added and incubated at $30{ }^{\circ} \mathrm{C}$ for $15 \mathrm{~min}$. The resulting lysate was vortexed vigorously before $1 \mathrm{mM} \quad \mathrm{MnCl}_{2}, \quad 10 \mathrm{mM} \quad \mathrm{MgCl}_{2}$ (Aldrich) and $200 \mathrm{mg} / 1$ DNase 1 (Pharmacia Biotech, St Albans, Herts, UK) were added and the lysate incubated for a further $30 \mathrm{~min}$ at $37{ }^{\circ} \mathrm{C}$. The lysate was then cleared by centrifugation at $2850 \mathrm{~g}$ at $4{ }^{\circ} \mathrm{C}$ for $30 \mathrm{~min}$ and stored at $-70{ }^{\circ} \mathrm{C}$.

\section{Protein purification}

Magnetisable cellulose/iron oxide particles were obtained from SCIPAC (Sittingbourne, Kent, UK).
Polyclonal goat anti-GST antibody obtained from Upstate Biotechnology was covalently coupled to the particles using the $1,1^{\prime}$-carbonyldiimidazole (CDI) method as previously described (AlAbdullah et al. 1989). The lysate containing the SF-1/GST-fusion protein was precleared by incubation with uncoupled particles for $4 \mathrm{~h}$ at $4{ }^{\circ} \mathrm{C}$, and the lysate was sedimented using a block magnet before incubation at room temperature with the particles coupled with the anti-GST antibody. The SF-1/GST-fusion was dissociated from the

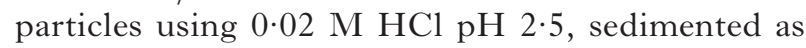
before using a block magnet and the supernatant was then neutralized with an equal volume of $0 \cdot 1 \mathrm{M}$ sodium phosphate (Aldrich) $\mathrm{pH} 7 \cdot 0$, filtered, then stored at $-20{ }^{\circ} \mathrm{C}$ until required.

\section{Cell culture}

The $\alpha$-SU expressing gonadotroph cell line $\alpha \mathrm{T} 3-1$, an adherent line (Dr P Mellon, University of California, San Diego, CA, USA), was cultured using standard procedures. Briefly, cells were grown in Dulbecco's modified Eagle's medium (DMEM) containing $10 \%$ fetal bovine serum, $1 \times 10^{5} \mathrm{U} / 1$ penicillin and $100 \mathrm{mg} / \mathrm{l}$ streptomycin (Life Technologies) at $37{ }^{\circ} \mathrm{C}$ in a humidified $5 \% \mathrm{CO}_{2}$ incubator and subcultured every $3-5$ days.

\section{Extraction of nuclear protein}

Nuclear extract was prepared from $\alpha \mathrm{T} 3-1$ cells in their exponential growth phase. Cells were washed twice with ice-cold phosphate buffered saline (PBS), before being scraped and pelleted by centrifugation at $8340 \mathrm{~g}$. Cells were resuspended in ice-cold PBS, pelleted a second time and resuspended in 5 packed cell volumes of buffer A $(10 \mathrm{mM} \mathrm{KCl}, 1.5 \mathrm{mM}$ $\mathrm{MgCl}_{2}, 10 \mathrm{mM}$ Hepes $\mathrm{pH} 7 \cdot 9,0.5 \mathrm{mM}$ dithiothreitol (DTT), 0.5 mM phenylmethylsulphonyl fluoride (PMSF), $0.1 \mathrm{mM}$ EGTA, $0.1 \mathrm{mM}$ EDTA, $100 \mathrm{mg} / \mathrm{l}$ aprotinin) (all supplied by Aldrich). Cells were left to swell on ice for 15 min before Nonidet P-40 (NP40) was added to a final concentration of $1 \mathrm{~g} / \mathrm{l}$, vortexed vigorously and left for a further 5 min to lyse the cells. The homogenate was pelleted for 20 seconds at $4{ }^{\circ} \mathrm{C}$ and the supernatant which represented the cytoplasmic fraction discarded. The nuclei were resuspended in 1 packed cell volume of buffer $\mathrm{B}\left(20 \mathrm{mM}\right.$ Hepes pH 7.9, $1.5 \mathrm{mM} \mathrm{MgCl}_{2}$, $2.5 \mathrm{~g} / \mathrm{l}$ glycerol, $420 \mathrm{mM} \mathrm{NaCl}, 1 \mathrm{mM}$ EGTA, $1 \mathrm{mM}$ EDTA, $0.5 \mathrm{mM}$ DTT, $1 \mathrm{mM}$ PMSF, $100 \mathrm{mg} / \mathrm{l}$ aprotonin) and extracted for $1 \mathrm{~h}$ at $4{ }^{\circ} \mathrm{C}$ with occasional mixing. The supernatant containing nuclear proteins was aliquoted and stored at $-70{ }^{\circ} \mathrm{C}$ until required. 


\section{Surface plasmon resonance (SPR)}

The BIAcore Upgrade was used in all experiments at a temperature of $25{ }^{\circ} \mathrm{C}$ with a flow rate of $10 \mu \mathrm{l} / \mathrm{min}$, with HBS used as both the dilution and flow buffer unless otherwise stated. Each new sensorchip was preconditioned before use by treating with two pulses of $50 \mathrm{mM}$ sodium hydroxide. The capturing of DNA to the surface of the sensorchip relies on derivatizing the carboxylated dextran matrix of the chip and subsequent conjugation via an amine to neutrAvidin and then the biotinylated oligonucleotide.

The surface of the sensorchip was activated using standard procedures. Briefly, after equilibration of the sensorchip surface with HBS, equal volumes $(35 \mu \mathrm{l})$ of NHS and EDC were mixed in equal proportions using an automated program, and $35 \mu \mathrm{l}$ were injected across the surface to activate the carboxymethylated dextran layer. Thirty-five microlitres neutrAvidin $(200 \mu \mathrm{g} / \mathrm{l}$ in $10 \mathrm{mM}$ sodium acetate (Aldrich) $\mathrm{pH} 4.5$ ) were injected across the flowcell. Excess reactive NHS esters were deactivated by injecting $35 \mu \mathrm{l} 1 \mathrm{M}$ ethanolamine $\mathrm{pH} 8 \cdot 5$ across the flowcell. The sensing surface was washed (regenerated) by injecting $30 \mu \mathrm{l} 0.5 \mathrm{~g} / 1 \mathrm{SDS}$ and $3.4 \mathrm{mM}$ EDTA (Aldrich). Typically, between 5000-7000 response units (RU) of neutrAvidin were immobilized on the chip. Target oligonucleotides (Table 1) were immobilized on the chip by injecting $35 \mu$ biotinylated double-stranded oligonucleotide $(70 \mathrm{pM})$. Non-covalently bound ligand was removed from the surface by injecting $30 \mu \mathrm{l}$ of the regeneration solution $(0.5 \mathrm{~g} / \mathrm{S} \mathrm{SDS}, 3.4 \mathrm{mM}$ EDTA $)$ twice. Specificity was tested by passing various concentrations of either bovine serum albumin or SF-1/GST fusion protein across a sensorchip with an unrelated ligand (alkaline phosphatase antibody) immobilized or where the sensorchip was activated but no ligand immobilized. Both the association $\left(k_{\text {ass }}\right)$ rate, and the dissociation $\left(k_{\text {diss }}\right)$ rate constants were determined from the binding rate of the protein to the sensorchip.

\section{Kinetic analysis}

The determination of kinetic rate constants on the BIAcore has been described previously (Karlsson 1994). The association rate equation that applies under the BIAcore experimental conditions is shown below.

$$
\mathrm{R}=\frac{k_{\text {ass }} \mathrm{CR}_{\text {max }}}{k_{\text {ass }} \mathrm{C}+k_{\text {diss }}} \quad\left[1-\mathrm{e}-\left(k_{\text {ass }} \mathrm{C}+k_{\text {diss }}\right) \mathrm{t}\right]
$$

where $\mathrm{R}=$ response $(\mathrm{RU}), \quad k_{\text {ass }}=$ association rate constant, $\quad k_{\text {diss }}=$ dissociation rate constant,
$\mathrm{C}=$ concentration of free analyte, $\mathrm{R}_{\max }=$ maximal response and $\mathrm{t}=$ time.

Assuming a model reaction of $\mathrm{A}+\mathrm{B} \leftrightarrow \mathrm{AB}$, a plot of $\mathrm{dR} / \mathrm{dt}$ vs $\mathrm{t}$ from the association part of the reaction has a slope $=k_{\mathrm{s}} . k_{\mathrm{s}}$ is calculated using a single exponential fit to the experimental data. Plotting $k_{\mathrm{s}}$ against $\mathrm{C}$ and using linear regression analysis, the slope of this secondary plot gives the $k_{\text {ass }}$.

$k_{\text {diss }}$ is determined from the dissociation phase of the interaction by plotting, $\operatorname{Ln}\left(\mathrm{R}_{\mathrm{o}} / \mathrm{R}\right)$ vs $\mathrm{t}$ where $\mathrm{R}_{\mathrm{o}}=$ initial response, and $\mathrm{R}=$ response at time $\mathrm{t}$. This plot should be linear with a slope $=k_{\text {diss }}$.

The goodness of fit of the experimental data to both association and dissociation models is assessed by Chi squared analysis. The affinity constant, $K_{\mathrm{A}}$ is calculated using the relationship $K_{\mathrm{A}}=k_{\text {ass }} / k_{\text {diss }}$ $\mathrm{M}^{-1}$.

\section{Statistical analysis}

Analysis of variance was determined using StatView ANOVA statistics, as the model can detect complex relationships between the independent and dependent variables. In this investigation, multiple comparisons were made using Fisher's protected least significant difference at the $5 \%$ significance level.

\section{RESULTS}

\section{Use of BIAcore to study SF-1-DNA interaction}

In order to investigate the interaction between the putative GSE and SF-1, biospecific interaction analysis using BIAcore biosensor technology was employed. To study the binding characteristics, biotinylated GSE oligonucleotide, a 2 bp mutant GSE oligonucleotide and a negative control CRE oligonucleotide (Table 1) were immobilized on a neutrAvidin-coated sensorchip. Full length purified SF-1 protein translated in vitro as described above bound in a concentration-dependent manner (Fig. 1a) to the immobilized GSE oligonucleotide. The concentration of neutrAvidin $(200 \mathrm{mg} / \mathrm{l})$ used to capture the biotinylated oligonucleotides has been described previously and results in saturated binding (Yang et al. 1995).

\section{Optimization of system}

A third concern, mass transport which can alter the binding progress curve and hence affect the kinetics of ligand association and dissociation was also addressed. Intrinsic reaction rate is flow 

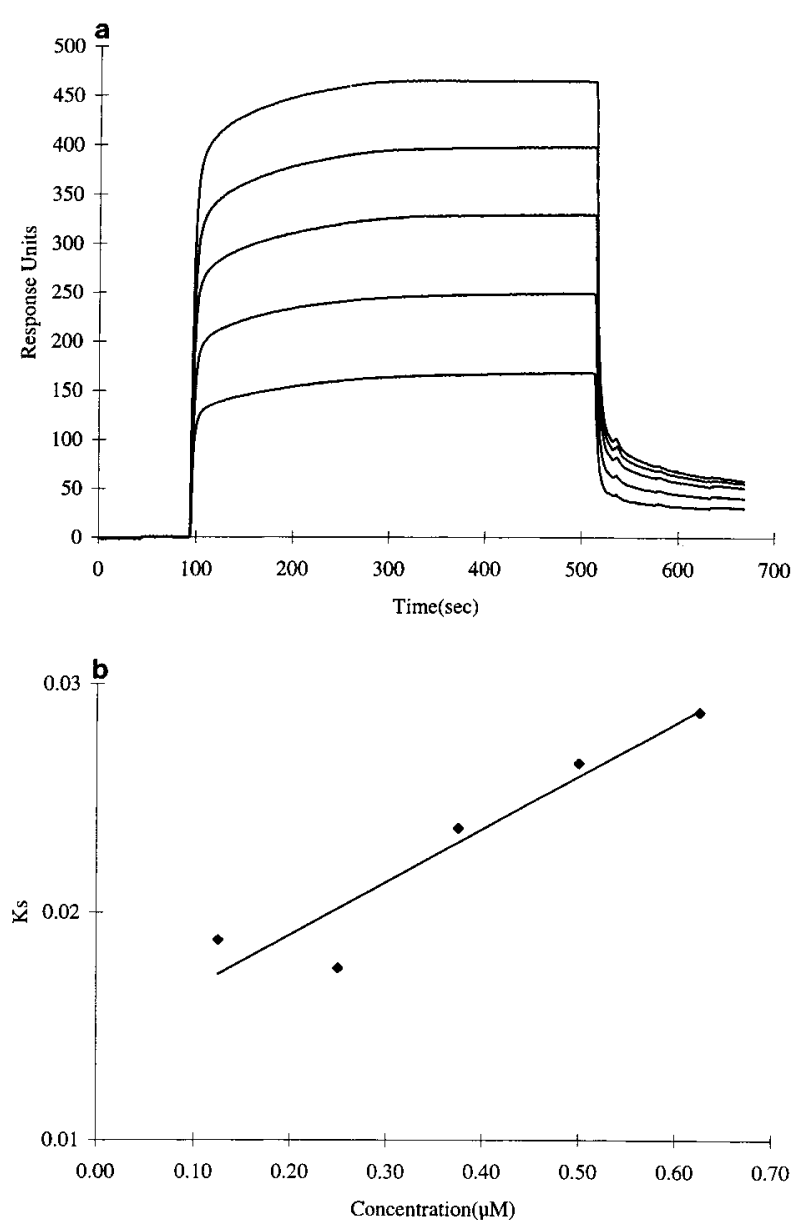

FIGURE 1. (a) The interaction of increasing concentrations of in vitro translated SF-1 protein $(0 \cdot 125-0 \cdot 625 \mu \mathrm{M})$ with the immobilized consensus GSE oligonucleotide presented as BIAcore overlay sensorgrams. (b) Data from (a) were used to plot the binding rate against the response for each concentration of SF-1. The slopes $\left(K_{\mathrm{s}}\right)$ of the resulting straight lines are then calculated. The slope of the plot $K_{\mathrm{s}}$ vs concentration gives the $k_{\text {ass }}$.

independent, therefore with the oligonucleotide GSE kept constant, the amount of protein bound was compared at different flow rates. Binding of SF-1 at a flow rate of $10 \mu \mathrm{l} / \mathrm{min}(170 \mathrm{RU})$ was greater than at $5 \mu \mathrm{l} / \mathrm{min}$ (93 RU), but with no further significant increase at 15 or $20 \mu \mathrm{l} / \mathrm{min}$, thus a flow rate of $10 \mu \mathrm{l} / \mathrm{min}$ was used in all analyses.

Specificity of binding was examined first by observing the effect of a non-specific protein (in vitro translated GST), which gave negligible background values (data not shown), and secondly, by demonstrating significant inhibition of binding using rabbit polyclonal immunoglobulin $\mathrm{G}$ anti-SF-1. This antibody has previously been shown to block the ability of SF-1 to bind to the promoter element of a number of genes including the gp $\alpha$-subunit (Barnhart \& Mellon 1994). Incubation of in vitro translated SF-1 protein with this SF-1 specific antiserum significantly decreased the binding of SF-1 in terms of relative RU to the immobilized GSE oligonucleotide after background subtraction of the bulk shift effect (Fig. 2), (SF-1: $60 \cdot 7 \pm 7 \cdot 5 \mathrm{RU}, \mathrm{SF}-1$ plus antibody: $23 \cdot 6 \pm 0 \cdot 6 \mathrm{RU}, P<0 \cdot 001$ ), while the addition of control antiserum had no effect. Additional experiments to assess the specificity of binding included the use of an unrelated oligonucleotide, NFIL6 (Table 1) or the addition of non-biotinylated GSE oligonucleotide to the SF-1 protein prior to injection. When biotinylated NFIL6 oligonucleotide was immobilized on the sensorchip and increasing concentrations of in vitro translated SF-1 protein $(0 \cdot 125$ to $0.625 \mu \mathrm{M})$ were injected, concentration-dependent binding was not observed and the mean binding seen across the range of concentrations was $12 \pm 3 \mathrm{RU}$ reflecting background or non-specific binding to a component of the stationary phase. Pre-incubation of in vitro translated SF-1 protein $(0 \cdot 625 \mu \mathrm{M})$ with $1 \mu \mathrm{M}$ non-biotinylated GSE oligonucleotide prior to injection eliminated binding of the SF-1 protein to the GSE oligonucleotide on the sensorchip (SF-1: $52 \cdot 1 \pm 7 \cdot 5$ RU, SF-1 plus GSE: $3 \pm 1 \cdot 0$ RU, $P<0 \cdot 001)$. The results from these experiments confirm that the GSE of the mouse $\alpha$-subunit gene promoter is bound in a specific and concentrationdependent fashion by in vitro translated SF-1 protein.

As shown in Fig. 1, binding occurred in a concentration-dependent manner for the GSE oligonucleotide and, indeed, similar concentrationdependent binding was seen with all oligonucleotides (data not shown). As expected, binding of SF-1 to the CRE oligonucleotide was greatly reduced compared with the GSE and $\mathrm{GSE}_{\mathrm{MUT}}$ oligonucleotides at all concentrations used.

\section{SF-1 shows differences in reaction rate constants for immobilized wild type GSE compared with the mutant GSE oligonucleotide}

Kinetic rate constants were obtained by measuring the interaction of the SF-1 protein at several different concentrations with each oligonucleotide. The association and dissociation rate constants for the SF-1 fusion protein were then calculated using the BIAcore kinetic evaluation $2 \cdot 1$ program. In all cases, the $k_{\text {ass }}$ and $k_{\text {diss }}$ were observed to be monophasic. Having controlled for all the different non-specific interactions that might interfere with the analysis, for example immobilizing the same 


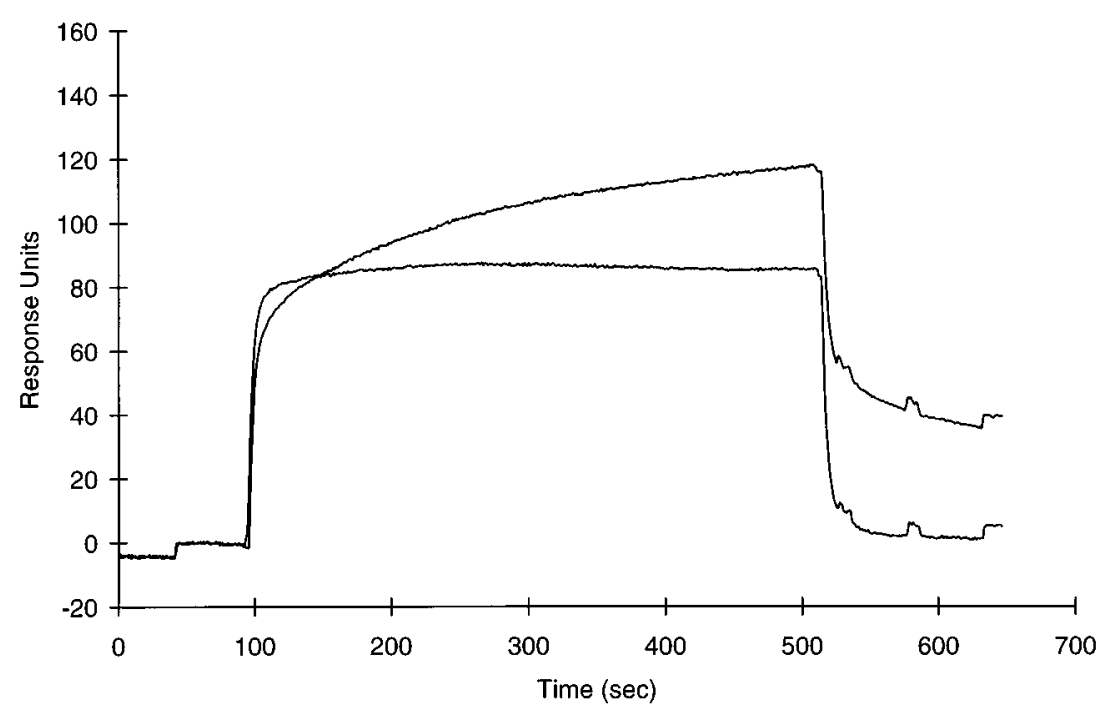

FIGURE 2. Superimposed sensorgrams of the interactions between in vitro translated SF-1 protein with the consensus GSE oligonucleotide incubated in the absence (top line) or presence (bottom line) of SF-1 specific antiserum.

molar concentration of each oligonucleotide on the sensorchip, the association/dissociation and affinity constants were determined for SF-1 (Table 2). When the dissociation constants were compared for the GSE, GSE ${ }_{\mathrm{MUT}}$ and CRE (negative control) short oligonucleotides, it was observed that there was an increase in the $k_{\text {diss }}$ value, $42 \%$ and $76 \%$ for the $\operatorname{GSE}_{\mathrm{MUT}}(P<0 \cdot 05)$ and the CRE (not significant) respectively compared with the GSE. Moreover, when comparing results for the $k_{\text {ass }}$, a twofold $(100 \%)$ difference was observed for the GSE oligonucleotide compared with the $\mathrm{GSE}_{\mathrm{MUT}}$ $(P<0 \cdot 01)$. This resulted in a threefold difference in the affinity $K_{\mathrm{A}}$ constant for the GSE compared with the $\operatorname{GSE}_{\text {MUt }}(P<0 \cdot 01)$.

The data generated from the above experiments was also analyzed by the BIAcore binding isotherm analysis program, an equilibrium binding analysis method. The $k_{\text {eq }}$ obtained from analysis of this data was very similar to that obtained by kinetic analysis (see Table 2). In particular, the threefold significant difference between the GSE and $\mathrm{GSE}_{\mathrm{MUT}}$ was still apparent $(P<0 \cdot 01)$.

\section{Oligonucleotide flanking sequences modify SF-1 reaction rate constants}

Further to establish the role of flanking sequences in the interaction of SF-1 with its consensus binding site, the GSE and $\mathrm{GSE}_{\mathrm{MUT}}$ oligonucleotides were synthesized such that an additional $7 \mathrm{bp}$ were added either side of the original oligonucleotides used (Table 1). Using these long oligonucleotides, there now appeared to be little difference between the dissociation constant for the GSE-L compared with the $\mathrm{GSE}_{\mathrm{MUT}} \mathrm{L}$ (Table 2). Differences were, however, still seen for the association $\left(k_{\text {ass }}\right)$ constants, $k_{\text {ass }}$ for the GSE-L showing an increase of $59 \%$ (not

TABLE 2. Kinetic parameters, affinity constants and equilibrium constants ( $k_{\mathrm{eq}}$ calculated by binding isotherm analysis) for the interaction of in vitro translated SF-1 protein and immobilized oligonucleotides. Results are presented as the means \pm S.E.M. of at least six determinations for each kinetic parameter

\begin{tabular}{|c|c|c|c|c|}
\hline & $\boldsymbol{k}_{\text {ass }}\left(\mathrm{M}^{-1} \mathrm{~s}^{-1}\right)$ & $\boldsymbol{k}_{\text {diss }}\left(\mathrm{s}^{-1}\right)$ & $\boldsymbol{K}_{\mathbf{A}}\left(\mathrm{M}^{-1}\right)$ & $\boldsymbol{k}_{\mathrm{eq}}\left(\mathrm{M}^{-1}\right)$ \\
\hline GSE & $5 \cdot 1 \pm 0.9 \times 10^{4}$ & $3 \cdot 8 \pm 0 \cdot 2 \times 10^{-3}$ & $1 \cdot 3 \pm 0 \cdot 2 \times 10^{7}$ & $5 \cdot 7 \pm 1 \cdot 5 \times 10^{6}$ \\
\hline GSE-L & $2 \cdot 1 \pm 0 \cdot 3 \times 104 * *$ & $3 \cdot 4 \pm 0 \cdot 2 \times 10^{-3}$ & $6 \cdot 9 \pm 1.4 \times 106^{*}$ & $6 \cdot 6 \pm 1 \cdot 8 \times 10^{6}$ \\
\hline $\mathrm{GSE}_{\mathrm{MUT}}-\mathrm{L}$ & $1 \cdot 3 \pm 0 \cdot 2 \times 104 * *$ & $3 \cdot 5 \pm 0 \cdot 1 \times 10^{-3}$ & $3 \cdot 8 \pm 0 \cdot 2 \times 106^{* *}$ & $2.9 \pm 0.4 \times 10^{6 *}$ \\
\hline CRE & $2 \cdot 9 \pm 0.4 \times 104 *$ & $4 \cdot 4 \pm 0 \cdot 1 \times 10^{-3}$ & $6 \cdot 0 \pm 0 \cdot 6 \times 10^{6 *}$ & N.D. \\
\hline
\end{tabular}

$* P<0 \cdot 05$ and $* * P<0 \cdot 01$ compared with the GSE for each column. N.D., not determined. 


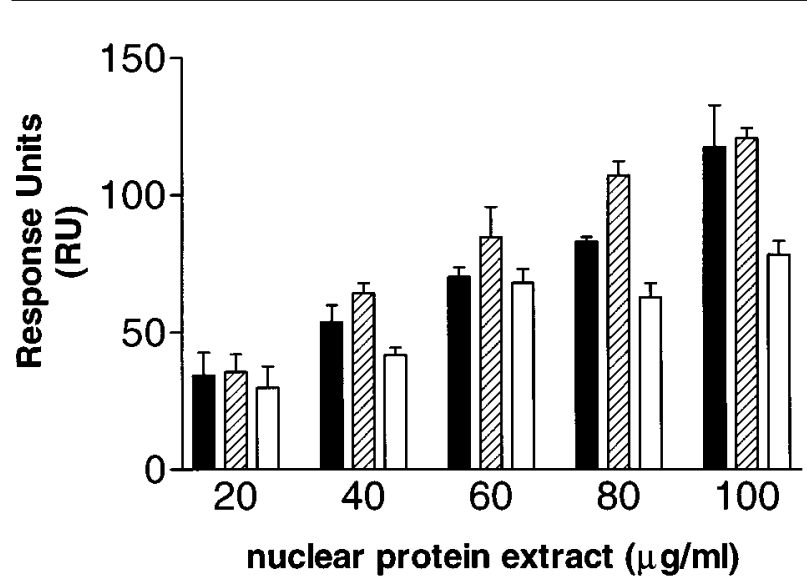

FIGURE 3. Binding of increasing amounts of $\alpha$ T3-1 nuclear protein extract $(20-100 \mu \mathrm{g} / \mathrm{ml})$ to the GSE (solid

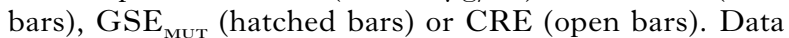
are presented as the change in response units (RU) after returning the system to buffer flow. Results are the means \pm S.E.M. of at least six determinations.

significant) when compared with the $\mathrm{GSE}_{\mathrm{MUT}}-\mathrm{L}$, although $k_{\text {ass }}$ for both the long oligonuclotides was significantly decreased when compared with the short GSE. When compared with the values obtained with the short GSE oligonucleotide, the affinity constants were significantly reduced for both the GSE-L $(P<0 \cdot 05)$ and the GSE MUT $-\mathrm{L}(P<0 \cdot 01)$. Thus in both cases, flanking sequences appeared to reduce the affinity for SF-1 protein.

\section{Analysis of oligonucleotide interactions using $\alpha \mathrm{T} 3-1$ nuclear extracts}

Nuclear extract prepared from the $\alpha$-subunit secreting gonadotroph cell line $\alpha \mathrm{T} 3-1$ was used as a crude source of SF-1 protein. The extract was used to study SF-1-DNA interaction in a more complex setting. The binding that occurred when increasing amounts of $\alpha \mathrm{T} 3-1$ nuclear protein extract was allowed to interact with the GSE, GSE $\mathrm{MUT}_{\mathrm{T}}$ and CRE is shown in Fig. 3. As before, binding occurred in a concentration-dependent manner for all oligonucleotides. As the precise amount of SF-1 protein in the heterogeneous nuclear protein extract was unknown, it was not possible to investigate association rates, and hence affinity constants. However, as the dissociation rate constant is not concentration dependent, it was possible to study the dissociation phase. Dissociation of SF-1 from the GSE, GSE and CRE oligonucleotides showed a monophasic pattern, with no significant differences observed between the different oligonucleotides. SF-1 was calculated to have a $k_{\text {diss }}$ of $1.5 \times 10^{-3} \mathrm{~s}^{-1}$ for the GSE and $k_{\text {diss }}$ of $2 \cdot 0 \times 10^{-3} \mathrm{~s}^{-1}$ for the GSE $\mathrm{MUT}_{\mathrm{MUT}}$,
TABLE 3. Calculated dissociation rate constants for interaction of nuclear protein extracts from $\alpha \mathrm{T} 3-1$ cells with immobilized oligonucleotides. Results are presented as means \pm s.E.M. of at least twenty individual determinations

\begin{tabular}{ll} 
& $\boldsymbol{k}_{\text {diss }}\left(\mathrm{s}^{-1}\right)$ \\
\cline { 2 - 2 } Oligonucleotide & \\
GSE & $1.5 \pm 0 \cdot 1 \times 10^{-3}$ \\
GSE $_{\mathrm{MUT}}$ & $2 \cdot 0 \pm 0 \cdot 2 \times 10^{-3}$ \\
CRE & $2 \cdot 1 \pm 0 \cdot 2 \times 10^{-3}$ \\
\hline
\end{tabular}

which indicates that SF-1 dissociates from the GSE oligonucleotide at a rate $30 \%$ slower compared with $\mathrm{GSE}_{\text {Mut }}$ (Table 3). No differences are observed for the $k_{\text {diss }}$ of the CRE oligonucleotide which was found to have a value of $2 \cdot 1 \times 10^{-3} \mathrm{~s}^{-1}$ similar to that seen for the $\mathrm{GSE}_{\mathrm{MUT}}$. However, when the dissociation rate constants are compared for in vitro translated SF-1 and crude nuclear extract derived SF-1, approximately threefold differences were observed (Table 2 vs Table 3). Dissociation of SF-1 from all oligonucleotides used in the investigation occurred $62 \%, 63 \%$ and $69 \%$ slower for the GSE, $\mathrm{GSE}_{\mathrm{Mut}}$ and CRE respectively than when using purified SF-1 protein suggesting that the presence of other proteins in the cell extract may affect SF-1-DNA interaction.

\section{DISCUSSION}

Numerous studies have established an essential role for SF-1 in endocrine development and function and as an important transcriptional regulator of a number of genes including key products of pituitary gonadotrophs (Barnhart \& Mellon 1994, Halvorson et al. 1996). However, the precise mechanisms involved in the regulation and expression of target genes by SF-1 remains obscure. To gain insight into the interactions that occur between SF-1 and its target DNA, we have used the technique of surface plasmon resonance to investigate the kinetics of interaction between SF-1 and its putative binding site in the $\alpha$-subunit promoter.

Using the BIAcore, we were able to monitor the binding of SF-1 protein to DNA and hence determine the association, dissociation and affinity constants for defined oligonucleotide sequences, including the consensus motif. By comparing the results obtained with consensus and mutant oligonucleotides, insights into the mechanisms involved in protein-DNA interaction were obtained. Using in vitro translated mouse SF-1 protein and oligonucleotides for the mouse GSE and mouse GSE $\mathrm{MUT}_{\text {, }}$, we demonstrated concentration-dependent binding 
to both sequences, with apparently reduced binding occurring to the sequence containing a $2 \mathrm{bp}$ mutant. Binding to the mouse GSE was shown to be specific since it could be reduced significantly in the presence of antibody to mouse SF-1 and excess non-biotinylated GSE.

It has been reported previously that the introduction of two $\mathrm{C}$ to $\mathrm{T}$ mutations in the mouse GSE oligonucleotide (termed $\mathrm{GSE}_{\mathrm{MUT}}$ ) eliminates the binding of SF-1 in both South Western blotting and gel retardation experiments (Horn et al. 1992, Barnhart \& Mellon 1994). These studies were performed using the GSE of the human $\alpha$-subunit promoter and nuclear extracts from $\alpha \mathrm{T} 3-1$ cells. To our knowledge no such experiments have been performed with the murine promoter and in vitro translated SF-1 protein, although Wilson et al. (1993) have described single nucleotide changes in the SF-1 binding site that either diminish or enhance SF-1 binding in gel mobility shift assays. It is of interest to note that the introduction of a similar $2 \mathrm{bp} \mathrm{C}$ to $\mathrm{T}$ mutation within the human LH $\beta$ GSE sequence, although blunting the ability of SF-1 to bind to this promoter, still allowed partial SF-1 responsiveness of the mutant construct in transfection assays (Halvorson et al. 1996), suggesting that some interaction still occurred. Using SPR we were able to show that a threefold reduction in the affinity constant occurred with this $2 \mathrm{bp}$ mutation and that this was due to both a reduction in the $k_{\text {ass }}$ and an increase in the $k_{\text {diss. }}$. It is tempting to speculate that this reduction in affinity is sufficient to blunt the ability of SF-1 to bind to this sequence under the conditions used in gel mobility shift assays. Other authors have also used SPR to demonstrate alterations in affinity constants following the introduction of point mutations in binding sequences (Malmborg et al. 1995).

The major advantage of SPR is that the protein-DNA interactions are monitored in real time and this allows detailed calculations of kinetic parameters, giving additional quantitative information to that obtained from gel shift assays. It has been reported that gel shift assays can be used in kinetic analysis (Hoopes et al. 1992) but are hampered by the need for recording a rapid reaction with a small number of data points - a technical difficulty being the lag time from the loading of the sample onto the gel to the separation of bound and free reactants. When relative rate determinations have been attempted using this technique, it has been reported to produce inconsistent results (Yang et al. 1995). Thus in contrast to SPR, gel shift assays do not provide a real time picture of the association events, although they are of benefit in binding specificity studies.
Previous data have suggested that the GSE consensus sequence alone cannot be sufficient for protein-DNA binding specificity and that flanking sequences may be involved (Wilson et al. 1993). We examined the effect of introducing $7 \mathrm{bp}$ wild-type flanking regions either side of the sequences for the GSE and GSE $_{\text {MUT }}$. Interestingly, introduction of flanking sequences reduced the affinity constant for SF-1, predominantly due to a reduction in the association rate constant. The observed differences in the affinity constant could be the result of secondary structural changes resulting in steric hindrance but this seems unlikely with such a short flanking sequence. Other SPR studies of transcription factor-DNA interaction have also suggested that flanking sequences can reduce protein binding and in some cases these flanking elements have been shown to compensate for observed differences between wild-type and mutant core motifs (Malmborg et al. 1995). Our data would also suggest that the addition of wild-type flanking sequences had more marked effects on the kinetic constants of the GSE compared with the $\mathrm{GSE}_{\mathrm{MUT}}$, although the functional consequences of such changes remain to be determined.

Using crude nuclear extracts from $\alpha \mathrm{T} 3-1$ cells we were also able to show a specific interaction with both the GSE and the $\mathrm{GSE}_{\text {мUт }}$. Again, the calculated $k_{\text {diss }}$ for the GSE was slower than that for the $\mathrm{GSE}_{\mathrm{MUT}}$. However, in both cases the $k_{\text {diss }}$ values were two- to threefold slower than those obtained with in vitro translated SF-1 protein, suggesting that secondary protein interactions might be occurring to account for these changes. Thus SPR may prove to be a useful tool in the kinetic analysis of transcription factor complex formation.

In conclusion, we have shown that the technique of SPR can be used to provide detailed kinetic parameters of the interaction between SF-1 and its consensus motif and in addition it can demonstrate the effects of mutations and flanking sequences on that interaction. Since, as described above, naturally occurring variants of the consensus GSE sequence are found both between species and in different target genes (Horn et al. 1992, Barnhart \& Mellon 1994, Halvorson et al. 1996, Parker \& Schimmer 1996) it would appear that SPR is a powerful technique for revealing differences in kinetic interactions between these sequences and their binding protein, SF-1.

\section{ACKNOWLEDGEMENTS}

We wish to thank Ms C L Davey for technical assistance with the BIAcore, Dr K Parker for the 
SF-1 cDNA and Dr P Mellon for the $\alpha$ T3-1 cells. This work was supported by the Biotechnology and Biological Sciences Research Council (Swindon, UK).

\section{REFERENCES}

Akira S, Isshiki H, Sugita T, Tanabe O, Kinoshita S, Nishio Y, Nakajima T, Hirano T \& Kishimoto T 1990 A nuclear factor for IL-6 expression (NF-IL6) is a member of a C/EBP family. EMBO Fournal 9 1897-1906.

Al-Abdullah IH, Mellor GS, Childerstone MS, Sidki AM \& Smith DS 1989 Comparison of three different activation methods for coupling antibodies to magnetizable cellulose particles. Fournal of Immunological Methods 122 253-258.

Barnhart KM \& Mellon PL 1994 The orphan nuclear receptor, steroidogenic factor-1, regulates the glycoprotein hormone $\alpha$-subunit gene in pituitary gonadotrophs. Molecular Endocrinology 8 878-885.

Bondeson K, Frostell-Karlsson A, Fagerstam L \& Magnusson G 1993 Lactose repressor-operator DNA interaction: kinetic analysis by a surface plasmon resonance biosensor. Annals of Biochemistry 214 245-251.

Deutsch PJ, Jameson JL \& Habener JF 1987 Cyclic AMP responsiveness of human gonadotropin-alpha gene transcription is directed by a repeated 18 -base pair enhancer. Fournal of Biological Chemistry 262 12169-12174.

Halvorson LM, Kaiser UB \& Chin WW 1996 Stimulation of LH $\beta$ gene promoter activity by the orphan nuclear receptor, steroidogenic factor-1. Fournal of Biological Chemistry 271 6645-6650.

Hoopes BC, LeBlanc JF \& Hawley DK 1992 Kinetic analysis of yeast TFIID-Tata box complex formation suggests multistep pathway. Fournal of Biological Chemistry 267 11539-11547.

Horn F, Windle JJ, Barnhart KM \& Mellon PL 1992 Tissue-specific gene expression in the pituitary the glycoprotein hormone alpha-subunit gene is regulated by a gonadotroph-specific protein. Molecular and Cellular Biology 12 2143-2153.

Japon MA, Rubinstein M \& Low MJ 1994 In situ hybridisation analysis of anterior pituitary hormone gene expression during fetal mouse development. Fournal of Histochemistry and Cytochemistry 42 1117-1125.

Johne B, Gadnell M \& Hansen K 1993 Epitope mapping and binding kinetics of monoclonal antibodies studied by real time interaction analysis using surface plasmon resonance. Fournal of Immunological Methods 160 191-198.
Karlsson R 1994 Real-time competitive kinetic analysis of interactions between low molecular weight ligands in solution and surface-immobilised receptors. Annals of Biochemistry 221 142-151.

Lala DS, Rice DA \& Parker KL 1992 Steroidogenic factor-1, a key regulator of steroidogenic enzyme expression, is the mouse homologue of fushi-tarazu-factor-1. Molecular Endocrinology 6 1249-1258.

Lala DS, Syka PM, Lazarchik SB, Mangelsdorf DJ, Parker KL \& Heyman RA 1997 Activation of the orphan nuclear receptor steroidogenic factor-1 by oxysterols. Proceedings of the National Academy of Sciences of the USA 94 4895-4900.

Laudet, V, Hönni C, Coll J, Catzeflis F \& Stéhelin D 1992 Evolution of the nuclear receptor gene superfamily. EMBO Fournal 11 1003-1013.

Malim MH \& Cullen BR 1991 HIV-1 structural gene expression requires the binding of multiple RE monomers to the viral RRE implications for HIV-1 latency. Cell $\mathbf{6 5}$ 241-248.

Malmborg A-C, Johansson K, Sigvardsson M, Borrebaeck CAK \& Leanderson T 1995 Real-time analysis of OCT protein-octamer interaction and transcription complex assembly. Molecular Immunology 32 1429-1442.

Morohashi K, Hoda S, Inomata Y, Handa H \& Omura T 1992 A common trans-acting factor, Ad4-binding protein, to the promoters of steroidogenic P-450 s. Fournal of Biological Chemistry 267 17913-17919.

Parker KL \& Schimmer BP 1996 The roles of the nuclear receptor steroidogenic factor-1 in endocrine differentiation and development. Trends in Endocrinology and Metabolism 7 203-207.

Simmons DM, Voss JW, Ingraham HA, Holloway JM, Broide RS, Rosenfeld MG \& Swanson LW 1990 Pituitary cell phenotypes involve cell-specific Pit-1 mRNA translation and synergistic interactions with other classes of transcription factors. Genes and Devopment 4 695-711.

Wilson TE, Fahrner TJ \& Milbrandt J 1993 The orphan receptors NGF1-B and steroidogenic factor 1 establish monomer binding as a third paradigm of nuclear receptorDNA interaction. Molecular and Cellular Biology 13 5794-5804.

Wong M, Ramayya MS, Chrousos GP, Driggers PH \& Parker KL 1996 Cloning and sequence analysis of the human gene encoding steroidogenic factor-1. Fournal of Molecular Endocrinology 17 139-147.

Yang WP, Wu H \& Barbas III CF 1995 Surface plasmon resonance based kinetic studies of zinc finger-DNA interactions. Fournal of Immunological Methods 183 175-182.

REVISED MANUSCRIPT RECEIVED 14 December 1998 